\title{
Assessment of Knowledge, Attitude, and Practice of Pharmacovigilance among Healthcare Professionals in Brazil
}

\author{
José Romério Rabelo Melo ${ }^{1,2, *}$, Elisabeth Carmen Duarte ${ }^{3}$, Karla de Araújo Ferreira ${ }^{1,4}$, Yannie Silveira Gonçalves ${ }^{1,4}$, \\ Marcelo Vogler de Moraes ${ }^{1,4}$, Paulo Sergio Dourado Arrais ${ }^{5}$ \\ 'Brazilian Health Regulatory Agency (Anvisa)/Inspection General Office, Brasília-DF, BRAZIL. \\ 2PhD Student at the Graduate Program of Pharmaceutical Sciences - Federal University of Ceará (UFC), Fortaleza-CE, BRAZIL. \\ ${ }^{3}$ Tropical Medicine Center, Faculty of Medicine, University of BRASILIA. \\ ${ }^{4}$ National Medicines Monitoring Center (CNMM) / Brazilian Health Regulatory Agency (Anvisa), BRAZIL. \\ ${ }^{5}$ Department of Pharmacy, Faculty of Pharmacy, Dentistry and Nursing, Federal University of Ceará. Fortaleza-CE, BRAZIL.
}

\begin{abstract}
Background: Adverse Drug Events represent a public health problem with high morbidity and mortality rates around the world. Knowledge, attitudes and practices of health professionals toward pharmacovigilance and reporting these events are important factors to promote safe drug therapy use. Objectives: The aim of this study was to evaluate Knowledge, attitudes and practices of health professionals and reporting of Adverse Drug Events by health professionals in Brazil. Methods: across-sectional study with a pretested questionnaire available online on the website of the Brazilian drug regulatory agency. Pharmacovigilance related Knowledge, attitudes and practices and Adverse Drug Events reporting were evaluated and correlations were estimated. Results: In total, 761 health professionals responded to the survey. The overall knowledge, attitudes and practices was of $57.7 \%$ for pharmacists, $56.9 \%$ for nurses and $40 \%$ for physicians $40 \%$ (considered to be a poor level). When evaluating performance by region, one physician (100\%) from the South region and one nurse from the Central-West $(83.3 \%)$ performed well on this indicator. Professionals in the age group older than 45 years and those with postgraduate degrees had the best performance in knowledge, attitudes and practices. The statistical analysis was performed with the software State version 15. Conclusion:
\end{abstract}

The study identified knowledge, attitudes and practices deficiencies in pharmacovigilance and mapped its main weaknesses, which makes it possible to better delineate measures to address these challenges and improve the Brazilian national pharmacovigilance system.

Key words: Adverse Drug Reaction Reporting Systems, Health Knowledge, Attitudes, Practice, Patient Safety, Pharmaco epidemiology, Product Surveillance, Post marketing.

\section{Correspondence}

José Romério Rabelo Melo

'Brazilian Health Regulatory Agency (Anvisa)/Inspection General Office, BrasíliaDF, BRAZIL.

${ }^{2} \mathrm{PhD}$ Student at the Graduate Program in Pharmaceutical Sciences - Federal University of Ceará (UFC), Fortaleza-CE, BRAZIL.

Phone: +085-98208-3808

Email: romerio.pgcf@gmail.com

DOI: 10.5530/jyp.2020.12.71

\section{INTRODUCTION}

Modern drug therapy has improved the way of managing and controlling diseases and is based on two essential factors: safety and effectiveness. ${ }^{1}$ Adverse drug event (ADE) continue to be a public health problem and its incidence is increasing worldwide,${ }^{2}$ with high rates of morbidity and mortality, especially among more vulnerable groups, such as children and elderly. Besides that, it can severely affect the costs of healthcare systems. $^{3}$

Spontaneous reporting of suspected ADE is one of the main pharmacovigilance tools, especially after the marketing authorization for a new drug. It is vital for the rapid detection of serious and rare ADE, guiding hypotheses of causality, investigation priorities and regulatory measures. However, it depends on the adequate knowledge, attitudes and practices of the health professionals towards the ADE notification. Since 2010, there has been an upward trend in knowledge, attitude and practice (KAP) studies among healthcare professionals, especially in developing countries and in pharmacy epidemiology field. ${ }^{4-6} \mathrm{KAP}$ research in the field of pharmacovigilance has not yet been extensively used, particularly in Brazil. However, some local studies indicate deficiencies regarding drug safety monitoring, knowledge about $\mathrm{ADE}$ and ADE notification forms. ${ }^{7}$ In this context, this study aims to assess the KAP among health professionals regarding pharmacovigilance and reporting ADE in Brazil.

\section{MATERIALS AND METHODS}

\section{Study design}

A cross-sectional questionnaire-based survey was conducted from January to April 2019, coordinated by the National Drug Monitoring Center (CNMM) of the Brazilian Health Regulatory Agency (Anvisa). No identification of the subjects was required and, therefore, it was not necessary to submit the study to Brazilian Research Ethics Committees, following Resolution No. 510/2016 of the National Health Council.

\section{Study questionnaire}

The questionnaire used in this study was based on a questionnaire from a similar survey conducted by the Australian Regulatory Authority (Therapeutic Goods Administration). The original questionnaire was translated into Portuguese language and, after semantic adaptation made by pharmacovigilance specialists, it was pretested with a sample of 174 Brazilian health professionals (data was not used in the analysis of this study). The questionnaire was divided into four sections: demographic characteristics, knowledge (Table 1), attitude (Table 2) and practice towards ADE reporting and pharmacovigilance (Table 3). 


\section{Study Population}

The target populations were nurses, pharmacists and physicians. They were invited to participate through the Anvisa website (http:// portal.anvisa.gov.br/noticias). Inclusion criteria were being a nurse, pharmacist or physicians and having answered at least $50 \%$ of all items in the questionnaire. Exclusion criteria was that the professional category was not identified in the questionnaire.

\section{Statistical analysis}

The three dimensions of KAP and the total score (sum of the scores in each dimension with appropriate responses) were analyzed. For the calculation of each dimensions, only participants who answered all the questions were included, whereas for the calculation of the total score all the answers of the three dimensions were used. In case a participant failed to answer a question from any dimension, the total score would not be calculated. To calculate the individual and total KAP score, answers were classified as "adequate" (one point) or "inadequate" (zero point) based on literature and Anvisa regulations (Tables 1-4). Participants with adequate answer for at least $70 \%$ of the questions were classified as "good level" and otherwise were classified as "poor level", following methodology conducted by Alshakka et al. ${ }^{8}$ The analysis was performed with the software Stata version 15. Fisher's exact test was used when appropriate and $p$-value less than 0.05 was considered statistically significant.

\section{Operational definition}

Adverse drug sevents (ADE): ADE refers to the unfavorable medical occurrence that can take place during treatment with a certain medication, but that does not necessarily have a causal relationship with the treatment. ${ }^{2}$

Pharmacovigilance: It is the science responsible for developing activities related to the detection, evaluation and prevention of drugrelated problems and its main objectives are the rational and safe use of medicines, besides evaluating and communicating risks and benefits of medicines in the market and information to patients. ${ }^{2}$

Knowledge: It is the ability to apply specific facts to solve problems or draw conclusions with the observation of a given event. Attitude: It is related to feelings, opinions, predispositions and beliefs, directed towards an objective, person or situation. Practice: It is the decisionmaking process to perform some action. ${ }^{4}$

\section{RESULTS}

In total, 761 questionnaires were returned to Anvisa met the inclusion criteria: mainly pharmacists (76.4\%), nurses $(19 \%)$ or physicians $(4,6 \%)$; from Southeast (54.4\%), aged between 25 and 44 years old (81.7\%) and had a postgraduate degree (72.9\%). $46.3 \%$ of the respondents claimed to know the concepts of Pharmacovigilance and to use this knowledge in their daily practice (Table 1). Having advanced knowledge and/or applying it in the daily routine was the second most selected answer to this question, with $32.2 \%$. Out of the total, $19.9 \%$ of the participants stated that they knew the concepts but did not apply them in their daily work practice. $44.9 \%$ of the participants stated that they acquired their knowledge in Pharmacovigilance during the daily practice of their activities and $30 \%$ at the university $(18.1 \%$ at undergraduate and $11.9 \%$ at graduate level).

Around $40 \%$ of the participants reported that the main motivating reasons for reporting $\mathrm{ADE}$ was the awareness that this attitude could reduce the risks in the use of medicines; or the awareness of the importance of building drug safety profiles (Table 2).

$67.7 \%$ of the participants said that they were under-reporters at least once in their lives and the main reasons that led them to not notify ADE were: lack of access to all the data needed to fill out the notification form (22.8\%), difficulties in accessing the notification form (16.1\%), lack of sufficient time and lack of feedback from the last notification made (14.3\%). Besides these reasons, $10.4 \%$ of the health professionals thought that making a notification was complicated or complex. According to the participants (52.5\%), the main factor that motivated the act of notifying was the existence of simpler notification system. (Data not shown).

$55.1 \%$ of the participants reported notifying ADE even when they were not sure about the causality between the drug usage and the event. Furthermore, $39.4 \%$ of pharmacists and $37.5 \%$ of physicians said that they reported only when they considered the ADE severe. Notification only in cases of certainty of causality between the event and the medication used was more prevalent among nurses (39.7\%) and pharmacists $(34.1 \%)$ (Table 2).

Table 1: Distribution of the variables of the knowledge dimension stratified by professional category.

\begin{tabular}{|c|c|c|c|c|c|}
\hline \multirow{3}{*}{ Level of knowledge(Adequacy) } & \multicolumn{4}{|c|}{ Professional category } & \multirow{3}{*}{$p$-value* } \\
\hline & \multirow{2}{*}{$\begin{array}{c}\text { Pharmacist } \\
n(\%)\end{array}$} & \multirow{2}{*}{$\begin{array}{c}\text { Nurse } \\
n(\%)\end{array}$} & \multirow{2}{*}{$\begin{array}{c}\text { Physician } \\
n(\%) \\
\end{array}$} & \multirow{2}{*}{$\begin{array}{l}\text { Total } \\
n(\%)\end{array}$} & \\
\hline & & & & & \\
\hline $\begin{array}{c}\text { Know the concepts and apply them } \\
\text { daily (Adequate) }\end{array}$ & $230(39.7)$ & $85(59.0)$ & $16(44.4)$ & $331(43.6)$ & $<0.01$ \\
\hline $\begin{array}{l}\text { Has advanced knowledge and apply it } \\
\text { daily (Adequate) }\end{array}$ & $205(35.3)$ & $25(17.4)$ & $15(41.7)$ & $245(32.2)$ & $<0.01$ \\
\hline $\begin{array}{l}\text { Know the concepts, but do not apply } \\
\text { them daily }{ }^{\star} \text { (Inadequate) }\end{array}$ & $124(21.4)$ & $25(17.4)$ & $2(5.6)$ & $151(19.9)$ & 0.04 \\
\hline $\begin{array}{l}\text { Awareness of the concepts, but do now } \\
\text { know how to apply it (Inadequate) }\end{array}$ & $18(3.1)$ & $9(6.2)$ & $3(8.3)$ & $30(3.9)$ & 0.06 \\
\hline $\begin{array}{l}\text { Do not know the concepts } \\
\text { (Inadequate) }\end{array}$ & $3(0.5)$ & $0(0.0)$ & $0(0.0)$ & $3(0.4)$ & 1.0 \\
\hline Total & $580(100.0)$ & $144(100.0)$ & $36(100.0)$ & $760(100.0)$ & - \\
\hline $\begin{array}{c}\text { Number of participants that did not } \\
\text { reply }\end{array}$ & 1 & 0 & 0 & 1 & - \\
\hline
\end{tabular}

* Fisher's exact test, $p$-value $<0.05$ was considered statistically significant. 
Most participants replied that they sent their notifications directly to Anvisa (52.4\%), pharmacists had the highest percentage, with 56.7\%. Among those who sent patients to the patient safety unit, nurses were the largest share, with $77 \%$, while $46.9 \%$ of doctors used to send notification to the record holder frequently (Table 3 ).

According to those surveyed, in general, the main places where they used to look for information about medicines was in medical-scientific literature, with $44.4 \%$ of participants and in the package leaflets, with $33.5 \%$. Physicians and nurses were the ones who most used the medicalscientific literature $(70.6 \%$ and $58.8 \%$ respectively), while pharmacists use the package leaflet more often, with $36.2 \%$. Anvisa's electronic file was the main source of access to package leaflets for $48.6 \%$ of the participants, especially for pharmacists, with $53.8 \%$ (Table 3 ). Finally, it was found that $43.6 \%$ of professionals who had knowledge in Pharmacovigilance applied their knowledge in their daily practice. Nurses were the ones who most applied this knowledge in their work routines.

\section{Analytical results of KAP assessment in Pharmacovigilance and ADE notification and their dimensions.}

The knowledge dimension was of "good level", since $75.8 \%$ of the participants chose adequate answers. Professionals from Southeast (79.7\%), Northeast (78.2\%) and South (73.0\%) regions, aged 25 and older $(>74 \%)$ and post graduated $(80.9 \%)$ had highest prevalence's of "good level". (Table 4).

The attitude dimension for the three professional categories was considered to be "poor level", since only $62,6 \%$ of participants chose adequate answers. (Table 4 ).

In general, the practice dimension was considered as "good level", since $78.2 \%$ of the professionals presented adequate responses. Only professionals who had not a postgraduate degree was classified as "poor level" in this dimension.

The total KAP score was calculated considering the answers from the three dimensions simultaneously and was found that the result of the professionals was considered as "poor level", since only $56.6 \%$ of responses were adequate. In general, the pharmacists (57.7\%) were rated better than other professional categories, although it was not observed statistical significance (Table 4).

\section{DISCUSSION}

The study included mainly pharmacists (76.4\%), professionals between 25 and 44 years old (81.7\%), residents in the Southeast region $(54.4 \%)$ and post-graduated (72.9\%). Pharmacists and physician had good levels, considering knowledge and practice. Regarding the "attitude" dimension, all categories of professionals had poor levels. The most participants informed that they had acquired this knowledge outside the university.

Table 2: Distribution of the variables of the attitude dimension stratified by professional category.

\begin{tabular}{|c|c|c|c|c|c|}
\hline \multirow{3}{*}{ Atitude(Adequacy) } & \multicolumn{4}{|c|}{ Professional category } & \multirow{3}{*}{$p$-value* } \\
\hline & Pharmacist & Nurse & Physician & Total & \\
\hline & $n(\%)$ & $n(\%)$ & $n(\%)$ & $n(\%)$ & \\
\hline \multicolumn{6}{|l|}{$\begin{array}{l}\text { a) What is the main reason to notify an adverse drug event } \\
\text { (ADE)? }\end{array}$} \\
\hline $\begin{array}{l}\text { It can lead to actions that reduce the risk associated to } \\
\text { medicines (adequate) }\end{array}$ & $206(36.7)$ & $74(53.2)$ & $17(50.0)$ & $297(40.4)$ & $<0.01$ \\
\hline $\begin{array}{l}\text { Reporting ADE is important to build drug safety profiles } \\
\text { (adequate) }\end{array}$ & $246(43.9)$ & $40(28.8)$ & $9(26.4)$ & $295(40.2)$ & $<0.01$ \\
\hline $\begin{array}{l}\text { Mandatory policies to report } \mathrm{ADE} \text { at workplace } \\
\text { (inadequate) }\end{array}$ & $61(10.9)$ & $18(12.9)$ & $6(17.7)$ & 85(11.6) & 0.4 \\
\hline I do not report $\mathrm{ADE}$ (inadequate) & $35(85.4)$ & $4(9.8)$ & $2(4.9)$ & $41(5.6)$ & 0.3 \\
\hline $\begin{array}{l}\text { Interest in obtaining scientific information about } \mathrm{ADE} \\
\text { (inadequate) }\end{array}$ & $11(2.0)$ & $3(2.2)$ & $0(0.0)$ & $14(1.9)$ & 0.9 \\
\hline Others & $2(0.4)$ & $0(0.0)$ & $0(0.0)$ & $2(0.3)$ & 0.9 \\
\hline Total & $561(100)$ & $139(100)$ & $34(100)$ & $734(100)$ & \\
\hline Number of participants that did not reply & 20 & 5 & 2 & 27 & \\
\hline \multicolumn{6}{|l|}{$\begin{array}{l}\text { b) Based on the last ADE reported by yourself, which were } \\
\text { the criteria used to define your attitude of notifying? }\end{array}$} \\
\hline $\begin{array}{l}\text { Report even when not sure about causality between drug } \\
\text { and adverse event (Adequate) }\end{array}$ & $270(52.9)$ & $79(60.3)$ & $22(68.8)$ & $371(55.1)$ & 0.1 \\
\hline Report when consider the ADE severe (Inadequate) & $201(39.4)$ & $46(35.1)$ & $12(37.5)$ & $259(38.4)$ & 0.7 \\
\hline $\begin{array}{c}\text { Report when convicted that the ADE was caused by the } \\
\text { drug (Inadequate) }\end{array}$ & $174(34.1)$ & $52(39.7)$ & $6(18.8)$ & $232(34.4)$ & 0.1 \\
\hline $\begin{array}{l}\text { Report when the ADE is not listed on the package leaflet } \\
\text { (Inadequate) }\end{array}$ & $172(33.7)$ & $27(20.6)$ & $7(21.9)$ & $206(30.6)$ & $<0.01$ \\
\hline $\begin{array}{c}\text { Report only ADE that are well known for the drug } \\
\text { (Inadequate) }\end{array}$ & $103(20.2)$ & $25(19.1)$ & $5(15.6)$ & 133(19.8) & 0.9 \\
\hline Number of participants that did not reply & 71 & 13 & 4 & 88 & \\
\hline
\end{tabular}

${ }^{*}$ Fisher's exact test, $p$-value $<0.05$ was considered statistically significant. 
As a matter of fact, few participants claimed to have acquired knowledge in pharmacovigilance at the university. In a Brazilian study showed that pharmacovigilance has not been yet incorporated into the curriculum as a discipline for undergraduate courses in the health area, besides revealing that disciplines as Pharmaco epidemiology have less than 2\% of workload at top pharmaceutical universities in the country. ${ }^{9}$ However, this problem does not seem to affect exclusively Brazil. Researchers from the United Kingdom ${ }^{10}$ and Portugal ${ }^{11}$ have shown that the amount of time dedicated to teaching pharmacovigilance in undergraduate and graduate pharmacy and medical courses is low. These results reinforce the need of greater attention at university education level to the subjects of Pharmacovigilance.

In general, it was observed that the participants of the study were "good level" in the knowledge dimension. This result was different from the study developed with health professionals from Ethiopia, ${ }^{5}$ Yemen and Saudi Arabia, ${ }^{8,12}$ where the professionals surveyed presented insufficient knowledge. The respondents from the Southeast region were those who obtained the highest percentages of correct answers to questions based on knowledge from Pharmacovigilance, while those from other regions the lowest proportions (data not shown), showing a regional contrast.

Table 3: Distribution of the variables of the practice dimension stratified by professional category.

\begin{tabular}{|c|c|c|c|c|c|}
\hline \multirow{3}{*}{ Practices mentioned (Adequacy) } & \multicolumn{5}{|c|}{ Professional category } \\
\hline & \multirow{2}{*}{$\begin{array}{c}\text { Pharmacist } \\
n(\%)\end{array}$} & \multirow{2}{*}{$\begin{array}{c}\text { Nurse } \\
n(\%)\end{array}$} & \multirow{2}{*}{$\begin{array}{c}\text { Physician } \\
n(\%)\end{array}$} & \multirow{2}{*}{$\begin{array}{l}\text { Total } \\
n(\%)\end{array}$} & \multirow{2}{*}{$p$-value } \\
\hline & & & & & \\
\hline \multicolumn{6}{|l|}{$\begin{array}{l}\text { To whom you are used to report an adverse drug events (ADE) } \\
\text { when you hear about one in your routine? }\end{array}$} \\
\hline Anvisa (adequate) & $298(56.7)$ & $57(42.2)$ & $8(25.0)$ & $363(52.4)$ & $<0.01$ \\
\hline Patient safety core (adequate) & $199(37.8)$ & $104(77.0)$ & $17(53.1)$ & $320(46.2)$ & $<0.01$ \\
\hline Owner of the patient record (Inadequate if choosed alone) & $220(41.8)$ & $28(20.7)$ & $15(46.9)$ & $263(38.0)$ & $<0.01$ \\
\hline Local health surveillance (adequate) & $118(22.4)$ & $14(10.4)$ & $4(12.5)$ & $136(19.6)$ & $<0.01$ \\
\hline Others & $12(2.3)$ & $4(2.9)$ & $0(0.0)$ & $16(2.3)$ & 0.9 \\
\hline Number of participants that did not reply & 55 & 9 & 4 & 68 & \\
\hline \multicolumn{6}{|l|}{$\begin{array}{l}\text { Where do you search for information about the medicine you } \\
\text { prescribe? }\end{array}$} \\
\hline In scientific literature (adequate) & $232(45.1)$ & $43(34.7)$ & $24(70.6)$ & $299(44.4)$ & $<0.01$ \\
\hline Package leaflet (adequate) & $187(36.2)$ & $31(25.0)$ & $8(23.5)$ & $226(33.5)$ & 0.03 \\
\hline Colleagues (inadequate if choose alone) & $6(1.1)$ & $12(9.7)$ & $0(0.0)$ & $18(2.7)$ & $<0.01$ \\
\hline Medicine/industry representatives (inadequate) & $7(1.3)$ & $3(2.4)$ & $0(0.0)$ & $10(1.4)$ & 0.7 \\
\hline Scientific conventions (inadequate if choosed alone) & $5(1.0)$ & $1(0.8)$ & $1(2.9)$ & $7(1.0)$ & 0.4 \\
\hline Others & $6(1.4)$ & $2(2.1)$ & $0(0.0)$ & $8(1.4)$ & 0.8 \\
\hline Number of participants that did not reply & 65 & 20 & 2 & 87 & \\
\hline \multicolumn{6}{|l|}{$\begin{array}{l}\text { In which circumstances do you consult the package leaflet of } \\
\text { medicines? }\end{array}$} \\
\hline Prescribing a medicine for the first time (adequate) & $227(50.6)$ & $57(58.8)$ & $22(64.7)$ & $306(52.8)$ & 0.13 \\
\hline $\begin{array}{l}\text { Patient reports the occurrence of an } \mathrm{ADE} \text { (inadequate if choosed } \\
\text { alone) }\end{array}$ & $218(52.5)$ & $41(45.6)$ & $10(33.3)$ & $269(50.2)$ & 0.08 \\
\hline Patient asks for information about a medicine (adequate) & $218(48.6)$ & $21(21.6)$ & $4(11.8)$ & $243(41.9)$ & $<0.01$ \\
\hline Prescribing a medicine that is new to the patient (adequate) & $149(33.1)$ & $39(40.2)$ & $8(23.5)$ & $196(33.8)$ & 0.18 \\
\hline Do not consult the package leaflet (inadequate) & $12(2.7)$ & $4(4.1)$ & $2(5.9)$ & $18(3.1)$ & 0.26 \\
\hline Number of participants that did not reply & 132 & 47 & 2 & 181 & \\
\hline \multicolumn{6}{|l|}{$\begin{array}{l}\text { Which source do you most use to access the package leaflet of } \\
\text { medicines? }\end{array}$} \\
\hline Anvisa (adequate) & $233(53.8)$ & $28(30.1)$ & $10(31.2)$ & $271(48.6)$ & $<0.01$ \\
\hline Web search engines (inadequate if choosed alone) & $115(26.5)$ & $42(45.1)$ & $17(53.1)$ & $174(31.2)$ & $<0.01$ \\
\hline Package leaflet inserted in the medicine (adequate) & $24(5.5)$ & $12(12.9)$ & $1(3.1)$ & $37(6.6)$ & 0.04 \\
\hline $\begin{array}{l}\text { Medicine applications for mobile devices (inadequate if choosed } \\
\text { alone) }\end{array}$ & $28(6.4)$ & $4(4.3)$ & $3(9.3)$ & $35(6.2)$ & 0.51 \\
\hline Website of pharmaceutical industries (adequate) & $19(4.3)$ & $3(3.2)$ & $1(3.1)$ & $23(4.1)$ & 0.92 \\
\hline Soft wares used to prescribe medicine (inadequate if choosed alone) & $8(1.9)$ & $2(2.1)$ & $0(0.0)$ & $10(1.8)$ & 0.83 \\
\hline Number of participants that did not reply & 148 & 51 & 4 & 203 & \\
\hline
\end{tabular}

${ }^{*}$ Fisher's exact test, $p$-value $<0.05$ was considered statistically significant. 
Table 4: Percent distribution of KAP (knowledge, attitude and practice) of participants on the national research about Pharmacovigilance and reporting of adverse drug events. Brazil, 2019.

\begin{tabular}{|c|c|c|c|c|c|}
\hline Variables & Knowledge & Attitude & Practice & KAP & \multirow{2}{*}{$P$-Value* (KAP) } \\
\hline & $n(\%)$ & $n(\%)$ & $n(\%)$ & $n(\%)$ & \\
\hline \multicolumn{6}{|c|}{ Professional category } \\
\hline Pharmacist & $435(75.0)$ & $304(61.2)$ & $181(80.4)$ & $128(57.7)$ & \multirow{4}{*}{0.42} \\
\hline Nurse & $110(76.4)$ & $87(68.0)$ & $40(69.0)$ & $33(56.9)$ & \\
\hline Physician & $31(86.1)$ & $20(62.5)$ & $12(80.0)$ & $6(40.0)$ & \\
\hline Total & $576(75.8)$ & $411(62.6)$ & $233(78.2)$ & $167(56.6)$ & \\
\hline \multicolumn{6}{|l|}{ Region } \\
\hline Southeast & $329(79.7)$ & $245(66.8)$ & $123(76.4)$ & $91(57.2)$ & \multirow{5}{*}{0.99} \\
\hline North & $22(61.1)$ & $15(51.7)$ & $12(75.0)$ & $9(56.2)$ & \\
\hline Northeast & $104(78.2)$ & $74(62.2)$ & $46(80.7)$ & $33(57.9)$ & \\
\hline Central-West & $37(60.7)$ & $30(58.8)$ & $15(78.9)$ & $10(52.6)$ & \\
\hline South & $84(73.0)$ & $47(52.2)$ & $37(82.2)$ & $24(54.6)$ & \\
\hline \multicolumn{6}{|c|}{ Age group (years) } \\
\hline$<25$ & $15(53.6)$ & $12(63.2)$ & $8(72.7)$ & $7(63.6)$ & \multirow{4}{*}{0.33} \\
\hline $25-34$ & $270(74.4)$ & $200(64.7)$ & $110(77.4)$ & $82(58.6)$ & \\
\hline $35-44$ & $200(77.8)$ & $143(63.3)$ & $77(75.4)$ & $50(49.5)$ & \\
\hline$\geq 45$ & $91(82.0)$ & $56(54.4)$ & $38(88.4)$ & $28(65.12)$ & \\
\hline \multicolumn{6}{|l|}{ Postgraduated } \\
\hline No & $127(61.9)$ & $102(61.4)$ & $50(61.7)$ & $35(44.3)$ & \multirow{2}{*}{0.01} \\
\hline Yes & 449 (80.9) & $309(62.9)$ & $183(84.3)$ & $132(61.1)$ & \\
\hline
\end{tabular}

* Fisher's exact test, $p$-value $<0.05$ was considered statistically significant.

Repeating the finding of 2016, when pharmaco governance, managed by Anvisa, was assessed and regional disparities in knowledge about pharmacovigilance in Brazil were identified. ${ }^{13}$

In the attitude-based questions, only $62.6 \%$ of the participants presented more than $70 \%$ of adequate answers. This result does not differ from other studies carried out in Brazil ${ }^{7}$ and in developing countries, such as India. ${ }^{14}$ Nurses were the ones who achieved the best performance in this dimension. In the present study, it was identified that health professionals expect better technological support to facilitate the use of the AMR notification system. ${ }^{15}$ In this sense, it is expected that with the new system adopted by Anvisa in 2019, (Vigi Flow system), the number of reports of ADE will increase.

The practice-based questions were the ones with highest percentage of professionals with adequate answers, with the pharmacists being the ones with best performance. These results differ from the results found in Jordan, ${ }^{16}$ which pointed out pharmacists with inadequate pharmacovigilance practices. These differences can be partially explained by different practices of the health services from each country. Nurses had the worst performance in the practical dimension, with $69.0 \%$ of adequate responses, like the study in Tehran, ${ }^{17}$ which also found low performance in practices related to pharmacovigilance. These results suggest the need for nurses to be more involved in drug safety.

In summary, the dimensions in this study that involved knowledge and practice of Pharmacovigilance were of a good level. However, the attitudes were considered inadequate (poor). A Similar finding was obtained in the KAP study in pharmacovigilance from Karachi (Pakistan) ${ }^{18}$
When evaluating the total KAP score, the results obtained are classified as "poor level". This finding is similar to that of other studies on the same topic in developing countries, demonstrating that this area still requires improvement. ${ }^{4-6,8,19}$

No significant statistical differences were found in the results of the total KAP score among health professionals, However, some particular groups stood out, which could be further investigated in future studies.

The observation of gaps between the dimensions of the KAP in this study shall be further investigated in future studies to create strategies to overcome them. A properly working pharmacovigilance system that gives adequate might induce knowledge, attitudes and appropriate health practices. Otherwise, the actions related to the notification of $\mathrm{ADE}$ become a major bureaucratic inconvenience, reflecting the inadequate practice of these professionals in this area.

The present study has limitations that shall be mentioned. Selection bias may have occurred since the sample studied did not meet a probabilistic process. Since one of the methods to obtain participants was through an open link on the Anvisa website, it is possible to assume that the greatest participation was from professionals already engaged in Pharmacovigilance activities. This fact may have over-represented the number of participants considered to be as "good level" in comparison to a situation at which professionals who are not so familiar with the topic had participated and for this reason, it is possible that the performance of the participants regarding the total KAP score may have been overestimated and, therefore, caution is advised in the interpretation and extrapolation of the present results. Information error may also have 
occurred, since the study worked with a self-administered questionnaire subject to interpretations, sometimes not completely accurate.

\section{CONCLUSION}

It was observed that health professionals from Brazil are as "good level" for knowledge and practice toward pharmacovigilance and were considered as "poor level" regarding attitude, which was identified as their main gap. In general, present study also identified deficiencies in KAP towards Pharmacovigilance, which makes it possible to guide better planning to face the challenges involved in strengthening the Brazilian Pharmacovigilance system. Finally, the expansion of coverage and content of training in Pharmacovigilance and the need for closer ties between Pharmacovigilance services and Brazilian universities are strategic actions which could impact this context in a positive way.

\section{ACKNOWLEDGEMENT}

The authors would like to thank the Anvisa Pharmacovigilance Management team for the support received and Sindusfarma, the Union of the Pharmaceutical Products Industry for their collaborations and the disseminating the research among your members.

\section{CONFLICT OF INTEREST}

The authors declare no conflicting interests.

\section{ABBREVIATIONS}

ADE: Adverse drug events; KAP: Knowledge, Attitude and Practice; CNMM: National Drug Monitoring Center; Anvisa: Brazilian Health Regulatory Agency.

\section{REFERENCES}

1. Datta S, Sengupta S. An evaluation of knowledge, attitude and practice of adverse drug reaction reporting in a tertiary care teaching hospital of Sikkim. Perspect Clin Res. 2015;6(4):200-6.

2. DaOrganização MS. Monitorização da segurança de medicamentos: diretrizesparacriação e funcionamento de um Centro de Farmacovigilância / Organização Mundial da Saúde - Brasília. Organização Pan-Americana da Saúde. 2005;48.

3. Stausberg J. International prevalence of adverse drug events in hospitals: An analysis of routine data from England, Germany and the USA. BMC Health Serv Res. 2014;14:125.
4. Thomas D, Zachariah S. Knowledge. Attitude and Practice of Pharmacovigilance in Developing Countries. In Social and Administrative Aspects of Pharmacy in Low-and Middle-Income Countries. Academic Press. 2018;177-93.

5. Shanko H, Abdela J. Knowledge, Attitudes and Practices of Health Care Professionals Toward Adverse Drug Reaction Reporting in Hiwot Fana Specialized University Hospital, Harar, Eastern Ethiopia: A Cross-sectional Study. Hosp Pharm. 2018;53(3):177-87.

6. Subramaniyan G, Gunaseelan V, Reddy K, Dharanipragada S, Adithan C. A Survey on Knowledge, Attitude and Practice of Pharmacovigilance towards Adverse drug reactions reporting among Doctors and Nurses in a Tertiary Care Hospital in South India. J Young Pharm. 2016;8(4):471-6.

7. Salviano LHMS, Luiza VL, Ponciano AMS. Percepção e condutas de profissionais da EstratégiaSaúde da Famíliaacerca de reaçõesadvers as a medicamentos. Epidemiol Serv Saúde. 2011;20(1):47-56.

8. Alshakka M, Bahattab OA, Ali H, Othman G, Ansari M, Shankar PR, et al. Comparison of the Knowledge and Perception of Pharmacovigilance Among Pharmacy, Dental and Medical Students in Aden-Yemen. J Pharm Pract Community Med. 2017;3(4):254-61.

9. Barreto M, Montagna E. Ainfluência da formaçãoacadêmica no conhecimento do farmacêuticoacerca da farmacovigilância e no papel que ele desenvolve na sociedade. Revista Acadêmica Oswaldo Cruz. 2014;2. Available from:http:// revista.oswaldocruz.br/Edicao_02/Artigos.

10. Smith MP, Webley SD. Pharmacovigilance teaching in UK undergraduate pharmacy programmes. Pharmacoepidemiol Drug Saf. 2013;22(3):223-8.

11. Corrêa-Nunes AM. O sistema de farmacovigilânciaem Portugal (suacriação e desenvolvimento). Cad Saúde Pública 1998;14(4):725-73.

12. Abdel-Latif MM, Abdel-Wahab BA. Knowledge and awareness of adverse drug reactions and pharmacovigilance practices among healthcare professionals in Al-Madinah Al-Munawwarah, Kingdom of Saudi Arabia. Saudi Pharm J. 2015;23(2):154-61.

13. Moscou K, Kohler JC, MaGahan A. Governance and pharmacovigilance in Brazil: A scoping review. J Pharm Policy Pract. 2016;9(1):3.

14. Bhagavathula AS, Elnour AA, Jamshed SQ, Shehab A. Health Professionals' Knowledge, Attitudes and Practices about Pharmacovigilance in India: A Systematic Review and Meta-Analysis. PLoS One 2016;11(3):e0152221.

15. Rishi RK, Patel RK, Bhandari A. Opinion of physicians towards adverse drug reactions reporting results of pilot study. J Community Nutr Health. 2012;1(1):25-9.

16. Suyagh M, Farah D, Abu FR. Pharmacist's knowledge, practice and attitudes toward pharmacovigilance and adverse drug reactions reporting process. Saud Pharm J. 2014;23(2):147-53.

17. Hanafi S, Torkamandi H, Hayatshahi A, Gholami K, Javadi M. Knowledge, attitudes and practice of nurse regarding adverse drug reaction reporting. Iran J Nurs Midwifery Res. 2012;17(1):21-5.

18. IffatW, Shakeel SR, Najia A, DrFakhsheena N, Shagufta GS. Pakistani physicians' knowledge and attitude towards reporting adverse drug reactions. Afr J Pharm Pharmacol. 2014:8:379-85.

19. Vigneshwaran E, Harichandana V, Jaffar S, Mohammad SAS, Khan N, Ahmed T. Knowledge, Attitude and Practice of Community Pharmacists towards Adverse Drug Reactions Reporting. J Young Pharm. 2020;12:75-80.

Article History: Submission Date : 14-03-2020; Revised Date : 09-06-2020; Acceptance Date : 18-07-2020

Cite this article: Melo JRR, Duarte EC, Ferreira KA, GonçalvesYS, Moraes MV, Arrais PSD. Assessment of Knowledge, Attitude and Practice of Pharmacovigilance among Healthcare Professionals in Brazil. J Young Pharm. 2020;12(3):255-60. 